\title{
Motivation for Writing the Paper What an Information System Is, and Why Is It Important to Know This: Why I Give Lectures and Seminars
}

\author{
Ray J. Paul \\ Department of Information Systems and Computing, Brunel University, Uxbridge, United Kingdom
}

\begin{abstract}
This paper discusses the author's motivations for writing the paper "What an Information System Is, and Why Is It Important to Know This", and how this relates to the approach taken in general in his lectures and seminars too. An explanation is given as to the motivation for this particular content of the quoted paper, and this paper then closes with a plea for simple explanations.
\end{abstract}

Keywords: information systems, information technology, education and dissemination

\section{Motivation for Writing a Paper}

When I give a talk of any kind, my opening slide consists of a title to the talk, my name, my current places of appointment and the label Discombobulator. The latter is an American word, meaning someone who disturbs, upsets or disconcerts. I tell my audience I will give as honest a view as I can of my subject matter, no matter if it disturbs etc.

The second feature of any talk I give is the purpose of my bothering to perform at all. When I ask my colleagues the purpose of a lecture, they often give some dreadfully dull responses. My view is as follows: a lecture is an opportunity to take a group of people on a journey of my choice; on the journey, I tell a story; if at the end of the journey people are still listening to my story, I know I succeeded. Confirmation for me is to see people leaving the lecture, holding animated conversations with other members of the audience about the ideas I have discussed in the lecture. I like to make people think.

\section{Motivation for the Contents of the Paper}

The paper I presented at ITI 2009, What an Information System Is, and Why Is It Important to Know This is a good example of what I mean. Information Systems as an academic subject has been blighted I believe by a lack of understanding of the basic nature of the subject itself. In the paper I offer a simple definition of Information Systems, that is

\section{"Information Systems is Information Technology in Use"}

You may not care for this definition, since you may be using the words Information Systems to mean something quite different. So let me offer:

\section{"Information Technology in Use"}

as being at the fundamental core of the problems associated with the automation of business, government and other economic and social systems. Why do I think it is fundamental? Because the implication of the "in Use" part of the definition is that this automatically includes consideration of the users of the systems, without whom the Information Technology could not be in use. And, when considering the users in combination with the Information Technology, it implies that at different points in time you will get a different view of the combination of the Information Technology and the way 
the users are using it to handle the operations of the organisation concerned at different points in time. In other words, the usage of the I.T. is dynamic, not static, and so "I.T. in Use" is timedependent, and therefore such a system cannot be built, it necessarily develops according to the way it is used.

If we examine Information Technology as a separate subject, we can speculate how to build such a system. If we look at users as a separate subject, then maybe we can speculate (through HCI or social psychology) how users can perform better. But neither approach will be addressing the fundamental issues concerning the combination of subjects suggested by "I.T. in Use". So from a research perspective, whilst there is nothing wrong with studying either of the two subjects independently, more benefit to society is more likely to come from the study of the combination. All specialists can contribute to the real problems of the world, without having to lose their subject identity. And what of the practitioners? "Information Technology in Use" is exactly the problem the practitioner faces, so experience suggests that far from being confused by the expression, in practice it has been found to be an effective short hand towards a common understanding of the underlying nature of the issues arising. In fact, this turns out to be true for any conversation about real world systems.

"Information Technology in Use" is a description of the basic nature of real world systems, but it would be helpful to give this a name. I would suggest that "information Systems" is a grand name, so that we have:

\section{"Information Systems is I.T. in Use"!}

If this expression gains wide acceptance, then maybe more research will be into real problems rather than the plethora of research being conducted in some theoretical fantasias (as evidenced by the papers published on Information Systems in academic journals).

\section{Simple is Best}

\section{"Information Systems is I.T. in Use"}

also meets a personal view I hold on how much one understands a particular problem or not. This view is that if something is understood well, it can be expressed simply, and if it cannot be expressed simply, it is not well understood.

Doubtless, the debate about what things are or are not will continue, but the challenge I pose to the community is whether to adopt this definition of what an I.S. is, or come up with a better (but simpler) alternative. My seven words take some beating!

ITI 2009 was the second conference that I had exposed what an I.S. is and this issue of CIT will be the first journal that the idea is presented in. I hope that makes clear how much I value both ITI and CIT.

Received: March, 2010 Accepted: April, 2010

Contact address:

Ray J. Paul

Department of Information Systems and Computing Brunel University, Uxbridge Middlesex UB8 3PH, U.K. e-mail: ray.paul@brunel.ac.uk

RaY J. PAUL, Emeritus Professor at Brunel University and Visiting Professor at the London School of Economics, both in the U.K., first attended ITI in 1988. He more or less fell instantly in love with Cavtat, the conference and another conference delegate. Since 1988 Ray has attended well over half the conferences to date, including some when ITI was held in Pula. Ray has also been a member of CIT's Editorial Board since it started, and this will be the fourth or fifth CIT special issue that Ray will have edited. 